to deal with questions of the purity of food and the prevention of adulteration.

THE number of small-pox cases in the epidemic in the East.End of London had reached over 40 by the middle of the week. Close supervision of suspects is being practised.

Professor W. E. Dixon, Professor W. H. Lang, Professor R. Muir, and Professor J. B. Leathes are among the candidates recommended by the Council of that body for election to the Royal Society.

\section{BONE-SETTING AND ITS GENERAL PRINCIPLES.}

\section{By Frank Romer, M.R.C.S. ENG., L.R.C.P. LoNd.}

SINCE Dr. Wharton Hood in 1871 described from personal observation the methods employed by Hutton, a leading bone-setter of the day, many surgeons have adopted, with satisfactory results, similar or modified principles. This article is submitted with the object of dispelling the popular notion that the medical profession know nothing of bone-setting, while at the same time drawing attention to the general principles which should be observed in dealing with joints whose utility has been impaired by adhesions. No useful object will be served by describing the pathology of the various ankyloses, and for the purposes of this article it may be assumed that reference is made to fibrous adhesions caused mainly by trauma. Again, though treatment by bone-setting is usually rapid and effective, it must be remembered that a cure could in many cases be achieved by electricity, prolonged massage, or other means.

Adhesions may appear within three weeks of the injury, but their capability of interfering with the action of a joint depends to a large extent on their situation. They may exist within the joint itself, binding together the articular surfaces and folds of synovial membrane, or be entirely periarticular when the surrounding tendons have become adherent to their sheaths through tenosynovitis. The resulting disability may vary from complete ankylosis of the joint to a condition where pain is only elicited by some particular movement. An important point to bear in mind is that a joint need not be entirely incapacitated by adhesions to require manipulation. Indeed, in these days of early massage and movement complete ankylosis is rare compared to what it was in the time when absolute rest was considered essential for the treatment of bone and joint injuries. Hence it frequently happens that the possibility of some small adventitious band is not suspected, provided the joint moves with comparative freedom, and it is especially in these cases that the modern bone-setter proves so successful. Careful examination in such cases will reveal a painful though comparatively slight interference with the normal range of movement, to cure which forcible manipulation will be just as necessary as in joints whose action is entirely crippled by adhesions. Some authorities state that previous to attempting these operations on ankylosed joints careful preparation for a week beforehand by hot fomentations and massage is essential. These preliminaries are not needful, though perhaps in certain cases of long standing, where the whole limb is stiff from disuse, a few radiant heat baths combined with massage might prove useful by rendering the muscles more supple. Again, it has been suggested that in such circumstances tenotomy should be previously performed, but proper attention to the aftertreatment makes this a quite unnecessary procedure.

Lnless contra-indicated, when adhesions are to be broken down an anxsthetic must always be given, not so much for the avoidance of pain as to ensure complete relaxation of the muscles. By dispensing with an anæsthetic the difficulties of the operation are increased, as it will be necessary to overcome muscles which the patient will involuntarily put into action for the protection of the joint, before the adhesions can be satisfactorily ruptured; at the same time, a risk is run of severely spraining or rupturing the contracted muscles. it is for the same reason that nitrous-oxide should not be selected as the anæsthetic, and it is possible that where severe inflammation has followed forcible movements these points have not been observed. Where manipulation has been properly performed no untoward result need be feared, as there is nothing in the rupture of fibrous bands to cause inflammatory action provided the case is otherwise suitable.

Generally speaking the movements should be performed in a swift, even, and firm manner, so that a joint undergoes the motions of its normal action, though not necessarily to the full extent of its range. The reason of this is that the muscles will have contracted in proportion to the limitation of movement permitted by the adhesions, and once that limit has been overcome the contraction of the muscles will be the only impediment to the normal range. The adhesions once ruptured after-treatment will speedily restore the elasticity of the muscles, which might well be strained should the full extent of movement be at once sought. In cases of long standing the adhesions yield with a distinct audible snap or crackle, others of less duration with the noise of tearing wet parchment, whilst those of still more recent date, though giving no audible sound, can generally be felt by the fingers of the operator. Experience shows that rapidity in the execution of the movements gives rise to far less after-pain than if the adhesions are broken down by slow and deliberate stretching, but care must be exercised against jerks or undue violence. When taking hold of a limb the grasp should be just above and just below the affected joint, for though a more powerful leverage can be obtained by more distant grips, yet it is as well to bear in mind that other structures may be broken besides adhesions, whilst in the young there is danger of separating the epiphyses.

After-pain is certain to be present in varying degrees, but will pass off in the course of an hour or so, and provided sufficient care has been taken in the operation no apprehension need be felt on this point. Within a few hours the joint should be gently massaged and movements aided. The mere allowing a joint to remain quiescent for 48 hours, as is sometimes recommended, is not safe; sufficient time may thus be given to allow the freshly ruptured adhesions to reunite. Notwithstanding the pain, every effort should be made to keep the joint free, and on no account should any bandage or splint be applied. It will be found that the rubbing, if skilfully performed, gives great relief from the pain, and any local application is scarcely ever requisite.

Occasionally full movement and freedom from pain follow the manipulations, but this ideal result is rare. More often a patient is quite unable to move the joint beyond the extent obtained under the anæsthetic, the explanation being that though there is no longer mechanical obstruction in the joint, the muscles from disuse are so wasted and contracted that they are physically incapable of normal work. To dismiss a patient without correcting this condition is to court almost certain failure. Merely ordering the joint to be used is for the most part useless, as few people have the strength of will necessary to make muscles perform their proper functions at the expense of pain. It is the custom of a large number of bone-setters to administer an anæsthetic on two or three subsequent occasions for the purpose of overcoming the muscular resistance. This should never really be necessary if the adhesions have been properly dealt with at the time of the operation, and the most satisfactory treatment after the first two days consists in substituting for the rubbing graduated exercises by means of weights and pulleys. These exercises, though possibly painful, must be performed daily, when it will be found that increase of strength and mobility bring decrease of pain. Exercises should be diligently persevered in till the muscles have regained their former bulk and the joint its full power of movement.

Such are the broad principles upon which bone-setting is based, and, though in certain particulars the procedure I have set out differs from that advised by some surgeons, it embodies the experience gained in a large number of cases, in which success has followed its adoption. Doubtless many joints affected by small adhesions might eventually recover by other means, but the facilities of radiant heat and massage are not easily come by in country places, and are moreover expensive. Where perfect recovery from effects of trauma is unduly delayed time is too often considered as the only solution of the difficulty, and when the patient, tired of his disability, seeks unqualified advice, his cure by the aid of "bone-setting" 
must not be regarded as one of " suggestion." Contrary to the popular belief that some mysterious gift is essential for the successful performance of these manipulations, there is nothing to prevent any practitioner doing them with success, provided that care is taken to ascertain the particular lesion that exists. A certain delicacy of touch is doubtlessly requisite to properly appreciate that lesion, whilst the correction of it largely depends on knack, but both can easily be acquired by experience and practice.

\section{THOMAS $v$. BARKER.}

Mr. Justice Darling's Summing-up.

IN the High Court of Justice, King's Bench Division, on Tuesday and Wednesday of last week, before Mr. Justice Darling, this important case was tried.

The following is a transcript from the shorthand notes of Messrs. Marten, Meredith, and Co., 8, New-court, Careystreet, London, W.C., of the summing-up of the learned judge, in the course of whose remarks the gist of the medical evidence becomes apparent as it struck an acute and impartial lay critic. The reasons both for the verdict in favour of the plaintiff and for the modest amount of the damages will be obvious.

Summing- $u p$.

Mr. Justice DaRLing: Gentlemen, you are aware that this is a caso in which the plaintiff seeks damages from the defendant, $\mathrm{Mr}$. Barker, becanse he says he has established before you, and it is for him to establish it, that Mr. Barker, undertaking to treat him for some affection of the knee, treated him without the amount of skill which be was entitled to expect from Mr. Barker, and that thereby the plaintiff that he had to have the leg amputated, which he would not, he says, otherwise have lost. Now, gentlemen, I tell you that it is for the plaintiff to satisfy you, or else your verdict must be given for the out. As to what that negligence should be, it is conceded that the defendant is a very skilful manipulator of bones; he is not a man who has passed examinations and got degrees, but has been a long time at this business, and everyone admits and it cannot be too well remembered that he has a great amount of skill and practice in dealing with affections of joints, dislocations of joints, as well as other injuries, which people may suffer from in their joints and limbs. That being so, he is bound to use the best of his skill and knowledge, and it will not do for him to say, and he does not say: "I am only a poor ignorant man, and I did my best." What he says is this: "I am a skilful man, I am a man who has performed thousands of remarkable operations resulting in cure where ordinary doctors bave been less successful," and it is because of that reputation that the plaintiff went to him, and and proper amount, of the skill and knowledge of the defendant to be placed at his disposal.

Now, gentlemen, there are some things in this case which we may take absolutely for granted. If I state anything that is not to be taken absolutely for granted 1 hope the learned counsel against whom I state from a state of knee which it is now admitted had resulted in from a state of knee which it is now admitted had resulted in his knee in 1901; it had been bad off and on in 1905 and 1906 his knee in 1901 ; it had been bad off and on in 1905 and 1906 and 1908 ; he had been at the Charing Cross Hospital, where the had been mare of his leg, of the joint, by the skilful photographer had been marie of his leg, of the joint, by the skilful photographer and doctor there, and he had come to the conclusion that then in 1908 at the Charing Cross Hospital the plaintiff was suffering from a that is before he sees the defendant at all. It may be also taken for granted that nothing that the defendant did, whatever it was, did produce or could have produced the tubercnlous affection uf the kneejnint; it is admitted that the tubarculous affection was present before. Now we know what has only lately been known, for a very few years the work of a little microbe; it is called a little bacillus, a thing that can be identified under the microscope, a thing that can be differentiated from other bacilli, so that a doct or will say, "That is a bacillus which produces tuberculosis; that is a bacillus which produces cholera; that is the bricillus which produces some other definite was such a thing as tuberculosis, and they called it tuberculosis, and they knew long ago that if you got a tuberculous joint you should keep it quiet, but they did not know why. But now the doctors know why, and the reason is that the bacilli are warring against the tissues in the human body, but among what the docturs call the forces of nature-the bacilli also ought to be recognised as the forces of nature, it seems to me-among the other forces of nature something at work which fights the bacillus, and what it does to him is to cover him over with an envelope. If you keep the place quiet where he is at work and cover him over with an envelope and imprison him, as long as he is there he is like the genius which the Eastern emperor put into the bottle and which the fisherman released like the gepius, he can do no harm, but take him out, release him, and he becomes active at once. He finds his way to the most, vital parts of the body and he will kill the patient in whom he is operating, unless he is removed by some such process as the amputation of the affected Mr. Thomas, and had been for a long time. Some of the doctors, the dectors on the one side, said, "We believe he was quiescent; we believe he had become quiescent; we believe he was imprisoner, encapsulated, use whatever term you like, and it would not hare
done him harm if it had not been interfered with." The doctors on bebalf of the defendant said this afternoon, "We do not agree at all." They said, "We bad not the same advantage; we had not the same opportunity as the plaintiff's doctors, because they saw the plaintiff while he had his leg upon him, they saw the sinus, they saw the abscess, they took off the leg, they examined while it was Iresb, bone, cartilage, tissues, and everything," and they were called yesterday and gave their evidence. The doctors called by the defendant thing since it has been preserved in formalin, and we come to the conthing since it, has been preserved in formalin, and we come to the conclusion that the microbes had not been encapsulated; that this was a
thing of long standing; that it was a progressive thing; it did become thing of long standing; that it was a progressive thing; it did become more active than it had been; it did result in such a thing that by the died." They all agree to that, but the defendant's doctors say that was in no way due to anything the defendant did, it would have happened anyhow. Then it becomes necessary to inquire what did the defendant do? Here, ggain, it is conceded on all hands, unless I am much mistaken, that it would have been grossly improper, with a leg being in the state in which it was in November, 1959, and December, 1909, to do any such thing to it as the plaintiff suggests was done. It would have heen grossly improper, the defendant himself says, to have used any violence
to it, to have attempted to break down adhesions by giving it a violent wrench.

Now, gentlemen, it is also admitted that in certain circumstances it is a perfectly proper thing to take hold of a joint and to use violence to it to break down adhesions. It is stiff because something has grown on to it and holds it tight, and it is admitted that there is a legitimate operdtion of breaking down adhesions, and then the joint will work. But it is armitter that must not be done if the joint is a joint affected by tuberculosis, and it must not be done for the reason that if you do that kind of operation upon a joint affected by tuberculosis you set free the bacilli and they do the work which I have just described to you. Now bacilli and they do the work which I have just describer to you. Now
the contest comes between the plaintiff and the defendant. The plaintiff says the defendant did undertake to perform an operation upon plaintiff says the defendant did undertake to perform an operation upon
him, the operation of breaking down the adhesions; he told me that he him, the operation of breaking fown the adhesions; he told me that he
would have medance, which he could not do while these adhesions were would have medance, which he could not do while these adhesions were
there. The defendant says, "I never undertook to do anything of the kind; I told you you had tuberculous disease of the joint." The kind; I told "you you had tuberculous disease of the joint." The plaintiff says "You did say something about tubercle, we talked about sometbing of the kind." The defendant says, "I told him that I must examine him, and I should recommend radiant-heat batbs, and I should want to examine the knee." The plaintiff said, "You told me you must give me an anæsthetic beeause the defendant says, "I never said anything of the sort. I wanted to perform no operation. I wanted to make an examination," and therefore the defendant says-I will read it if you wish, but I think I can summarise it - "I recognised from the first this was a very bad knee. I suspected there might be cancer it was so bad, sarcoma it is called. I never expected even to be able to give relief, but I said I will try these radiant-heat baths and make the examination, and I shall want, for the examination, to give you an anæsthetic." Gentlemen, he did prescribe the heat baths, and the plaintiff took them, and he went back, and on defendant got Dr. Axham, his anresthetist, to gire gas to the plaintiff. While under gas he did something to the plaintiff, and he did it with his hands. The defendant says, "What I did was $I$ handled him very gently, I simply moved my hands during a few seconds to make an examination." Why did he do it? He said. "I did it to contirm myself in my opinion. I had made a hurried examination before, and this was to satisfy myself whether my first opinion about it was right." If the very first examination, the one on the 27 th November, did satisfy him he was quite right that it was tuberculosis, that there was nothing to he done, the case was hopeless-he said himself there was notbing for it but amputation, and that he told the
plaintiff so, and that he must see a surgeon-If that is so, how is the plaintiff so, and that he must see a surgeon-If that is so, how is the second examination explained? What is said is, if you are going to
treat a leg in the way of breaking down adhesions, if you do not break them all down the first time you will bave to perform a subsequent operation. That is common enough, but it is asked, If he bad made an examination under gas and sat isfied himself by that examination of the to 5 guineas more to 5 guineas more expense to make another examination? The answer produced. Now are you satisfied of that? Dr. Axham has been called, you have heard his evidence. I will not attempt in anv way-it is se lately given and it would be impossible to summarise it in a few wnrds - to convey any idea of it. You have heard it. Does it satisfy you no operation was performed on that day? Does it satisfy you
there was nothing else? You heard his examination and his cross examination. There is the fact of what is put down in the books. You see "Op. gas" and those two letters and you have heard the defendant's explanation of what that means. They are the very words be puts down when he does do an operation, when he does operate by breaking down adhesions. There is nothing to distinuish them, but he says: "It merely means I wanted the anzsthetist; Gentlemen mean there was an operation, it merely means gas." why not put down only "Gas": why put "Op. gas," which is put when there is an operation under gas, if you do not mean any operation but only mean gas? But there is his explanation. It seems certain that gas is quite sufficient if you are only going to do such an operation as can be done by a very skilfu? man, a very quick man. Gas is quite sufficient if a skilful practised man is going to break down adhesions, might take you or me half a day, but a man who knows exactly what might take you or me half a day, but a man who knows exactly what
to docan do it; and the defendant habitually does do it with gas. Whes: he wants to perform an operation he puts "Op. gas," and then he per-
he forms an operation not with chloroform or ether necessarily, but with forms an operation not with chloroform or ether necessarily, but with
nitrous oxide gas. If that is so, you must ask yourselves are you satisfied what was done on these days was nothing but examination. If it was nothing but examination the plaintiff's case is gone, because nobody pretends that merely to examine that knee without using the sort of violence that would be used to break down 